\title{
Study on the Paths and Ways of New Village Elites' Participating in Rural Community Governance in the New Era
}

\author{
Xinping Yuan \\ New Rural Construction Research Center \\ Wuhan University of Science and Technology \\ Wuhan, China 430000
}

\author{
Jiatong Li \\ New Rural Construction Research Center \\ Wuhan University of Science and Technology \\ Wuhan, China 430000
}

\begin{abstract}
In recent years, many scholars have carried out new discussions and studies on new village elites' participation in rural governance. However, many of the scholars did not discuss the above issues in the macro perspective in the context of studying new village elites' participation in rural governance. On the microcosmic, we only study the governance of the whole rural area and neglect the governance of the rural community as the more basic unit in the grass-roots level. The significance of this paper lies in combining the background of the new period with the governance path and way of new village elites' participation in rural communities' research and analysis, and summing up how to better promote rural community governance.
\end{abstract}

Keywords—new era; new village elites; rural community governance

\section{INTRODUCTION}

In recent years, village elites are returning to rural construction in a variety of ways. In the context of the 19th National Congress of CPC, the new era has also given new meaning to village elites. General Secretary Xi Jinping put forward new tasks and new requirements for socialist construction in the 19th National Congress of the Communist Party of China, including strengthening the construction of new countryside in light of the background of the times. Rural community governance is an important part of the new rural construction. In recent years, the attention paid to rural community governance as a grassroots unit is far from enough. In the past, many scholars have conducted a series of researches and discussions on the participation of village elites in rural governance. This paper will analyze the characteristics and advantages and disadvantages of village elites in combination with the background of the new era, and discuss the way for new village elites to better participate in the grassroots rural community governance.

\section{OVERVIEW OF RURAL GOVERNANCE IN THE CONTEXT OF THE NEW ERA}

This chapter will introduce the past and current situation of rural community governance in the context of the new era from the historical changes of rural community governance, its new problems in the new era, and the background of the new era.

\section{A. Basic Theory of Rural Community Governance}

This section will start from the historical development of rural community governance, and describe and analyze the new problems faced by rural community governance in the new era.

1) Historical changes in the way of rural community governance: In the traditional period, rural community governance was in a state of "autonomy". These characteristics were derived from the blood and regional nature of the early society. Due to the traditional period, the rural grassroots are not directly governed by the country, let alone the communities in the village. Some of the name in traditional times, such as New Village and Liu Village, reflect that the villages at that time were based on blood. In this context, the management of the village will naturally be in a state of self-development and self-governance. This kind of management relies on the prestige and knowledgeable people in the village to be responsible for it, which is reflected in the township heads, village heads, and squire, etc., especially the squire. The predecessors even have the saying that "if the imperial power does not go down the county, the county only has the squire". In the condition where squire obtains the acquiescence of the imperial power, they integrate various social resources to manage the village through its own resource advantages.

In the modern times, the governance of the country has gradually penetrated into the grassroots, which is the inevitable result of the strengthening of the country's dominance and an important indicator of the transformation from traditional countries to modernized countries. And in modern times, the governance of rural communities has gradually shifted to "political parties", mainly because of the "political parties" of Chinese society in modern times, such as the Communist Party leading farmers to carry out land reform, county autonomy proposed by Sun Yat-sen, and rebuilding rural order and so on. 
After the founding of New China, the governance of rural communities showed "politicization". As China entered a new era of modernization, the country began to transfer construction tasks and centers to the governance of rural grassroots communities, clean up feudalism, and rebuild the community governance system of rural areas. They also gradually use various policies to support the rural economy, so that the rural grassroots community governance is gradually standardized and institutionalized. In recent years, China has proposed strategies such as urban-rural integration and rural revitalization, and has put forward further requirements and goals for rural grassroots governance.

2) New problems facing rural community governance: From the perspective of government, in recent years, rural society has a major feature - open mobility which is not only in the rural areas, but also become a new external environment for rural community governance. It is in this open and flowing environment that the entire rural community governance is gradually changing from the economic base. However, facing these changes and the open and flowing environment, there is huge a contradiction between the existing phenomena of the integration of village and community and mix of political and economic in the actual situation. The open and flowing environment requires the free flow of personnel, but due to the old collective property rights system and household registration system, the rural community has evolved into a closed environment in which there is internal restraint and external exclusion. Such a closed environment is a new problem in the current governance of rural communities. The direct connection between state power and farmers, coupled with the reform of taxes and fees, has, in some respects, enhanced the country's attention and management at the grassroots level and guided the transformation of rural community governance, but from other perspectives, the state's excessive intervention has made the rural grassroots government virtual, and the relationship between the state and the peasants has indeed become closer, which has affected the governance of the rural communities by the grassroots government. The grassroots government is placed in the middle of the state and the countryside, but it can't play the required role, and has also greatly stricken the enthusiasm of the grassroots government. The agricultural tax was abolished, but the central government's financial transfer payment was not enough to make up for the lack of agricultural tax. The township government was already overhead, and the economic operation was difficult, which made the autonomy level of countryside lower and rural governance unable to develop.

From the perspective of rural autonomy, since the rural society is subject to the urban-rural dual system, rural areas are actually in a relatively weak position. Therefore, the rural areas are not economically effective. The rural governance mainly relies on the preferential policies of the state to the grassroots organizations, but they lack the driving force for development. Secondly, there is the problem of "empty-nest society" in rural areas, which means the rural public participation is limited. Then, with the acceleration of urbanization, fault phenomena appear in rural social culture.

\section{B. Rural Community Governance in the New Era}

In the second section, the author expounds the concept of "new era" and introduces some national policies for rural community governance in the new era.

1) Definition and characteristics of the new era: The new era of socialism that we often refer to now mainly refers to a new era of socialist construction that China enter since the Third Plenary Session of the Eleventh Central Committee in December 1978. After decades of reform and opening up, we have found the right path to adapt to China's contemporary national conditions, and the country has embarked on the road of prosperity and strength. Today, at the 19th National Congress of the Communist Party of China, General Secretary Xi Jinping has announced that socialism with Chinese characteristics has entered a new era and the new period transformed into a new age. This is a sign that the socialist cause with Chinese characteristics has reached a new milestone. Therefore, this article defines the new era from the beginning of socialist construction to the present, including the new age after the transformation of the new era.

Under such a new era, China has gone through the process of "getting rich" and is trying to move forward to "becoming strengthener"; in this new era, China is no longer at a low starting point, but at a high starting point that is based on the people's prosperity; in this new era, although it is highly recognized and praised by people, our party and people are still facing greater challenges. On this road of strong party, strong army, and strong country, it won't be smooth sailing.

2) Policies for rural community governance in the new era: In the new era, in order to promote grassroots governance in the new countryside, the government has promulgated many favorable policies, mainly starting from the economic foundation. In recent years, there are urbanrural integration, the abolition of agricultural taxes, and the establishment of a rural labor security system and so on. The most cutting-edge and latest policy is the "rural revitalization" strategy proposed by the 19th National Congress. President $\mathrm{Xi}$ stressed that it is necessary to promote the modernization of agriculture and rural areas and the long-term stability of land contracting relations. Secondly, President Xi also stressed that in the governance of rural communities, we must pay attention to the combination of self-governance, government by law and rule of virtue, especially to strengthening the rule of law.

\section{THE OVERVIEW ON VILLAGE ELITES}

In this chapter, the author introduces the historical changes of village elites and the characteristics and advantages of present new village elites. 


\section{A. Historical Changes of Village Elites}

In the past, "village elites" was called the squires. Generally speaking, it refers to people in the village who are respected by the peasants and have prestige in the village because of their high level of knowledge and good moral character. In the past, squires are the key point and foundation for governing the village. Because the country generally did not intervene in the management of the village, it only relied on communicating with the special class of squire, let the squire as the responsible person manage the village. Such a governance method makes rural governance highly autonomous. More specifically, the past squire bears the role of the conveying message between people and government, and their mission is to carry on the cultural inheritance in the countryside, the education of the people, the promotion of public welfare, the maintenance of the rural order, and the development of rural economy and so on. Therefore, in the past, squire represented the development of rural society.

With the changes of the times, the village elites are no longer the squires of the past. The people who constitute the village elites are not the original class and its connotation of the times has also undergone tremendous changes. The new village elites and the traditional culture are relatively identical in terms of personal qualities. They all have a high level of cultural knowledge and have good ideology and morality, but new village elites focus more on the individual's contribution to the prosperity and development of hometown. This behavior is selfless and noble, and has no interest relationship with the government. They are not necessarily rooted in the countryside to contribute, but they are always in touch with the countryside, and they can serve the construction of the country anytime and anywhere.

1) Characteristics of new village elites: Compared with the traditional village elites in the past, new village elites have common points as well as differences. First, new village elites have the same regional characteristics as the traditional village elites. In the past, the squire accepted the acquiescence of the imperial power to manage the village. Although the starting point is different from that of the traditional village elites, new village elites still has this characteristic because they want to go home or make social contributions to their hometown. Second, the same as the traditional squire, new village elites also have a very high social prestige. Their knowledge level is generally high and their ability is strong. Third, unlike traditional squires, new village elites tend to be popularized. They don't emphasize the family background, social status, and power and resources in its hometown like squires, but are more inclined to contribute to the countryside. These people have a sense of responsibility and a sense of justice. They are intellectuals trusted by the masses of the rural community. Fourth, in the new era, new village elites carry the core values of socialism and the advanced culture of socialism. They can spread these cultures and positive energy in the governance of rural communities and actively cultivate the socialist values of the masses. Finally, due to its high level of knowledge and culture, new village elites have a sense of democracy and the rule of law in their consciousness. Their way of thinking is at the forefront of the times and is keeping pace with the party. One of their working principles is the principle of the rule of law, so they obey the law resolutely.

\section{OVERVIEW OF NEW VILLAGE ELITES' PARTICIPATION IN RURAL COMMUNITY GOVERNANCE IN THE NEW ERA}

In this chapter, the author discusses the advantages for new village elites to participate in rural community governance and problems that may occur.

\section{A. Advantages and Significance of New Village Elites for Rural Community Governance}

In the article, we introduce the characteristics of new village elites, which cover some of the advantages: first of all, new village elites are different from the squires who implement the process of autonomy by relying solely on the acquiescence of the imperial power. In the new era, new village elites are a hub connecting the grassroots of the rural community with the government. In this role of the hub, new village elites can do a good job in communicate, and they has regional characteristics in the rural areas, so it has a wide range of personal advantages and prestige advantages, which brings many conveniences to rural community governance. They are often able to integrate rural areas more quickly and effectively and make resource allocation more reasonable.

Second, in the process of promoting the progress of rural community governance, new village elites can also play a unique advantage in economic development. In the past, the rural areas needed great support from the government, including focus on policy and poverty alleviation on economic development, etc., but these are not a real driving force for rural development. New village elites themselves have a high level of cultural knowledge, and they have ideas and capabilities. Therefore, they can use the resources on hand to guide community farmers to carry out more efficient economic activities under the conditions of communication with the government.

Third, new village elites themselves are a high-quality group that has been educated in the new era of socialism. They have a deeper understanding of the theory of socialist construction in the new era and the theory of the rule of law in the new era, and can bring the socialist core values and the ideological concepts of the rule of law in the new era in rural areas to improve the quality of farmers, strengthen the rule of law in rural areas, and contribute to the better promotion of rural community governance.

Finally, under the new era, new village elites relies on their own understanding of the hometown or the country, and in the face of the gradual disappearance of rural civilization, they can use their high-level culture and flexible methods to retain the precious local culture and history of the countryside and develop it into a characteristic of rural areas to govern through a certain way to give full play to the advantages of its local rural areas and make full use of its resources. 


\section{B. New Problems in New Village Elites' the Participation} in the Governance of Rural Communities in the New Era

From the conversion of squire to village elites, old village elites to new village elites, the problems and challenges faced by village elites in participating in the governance of rural communities are also changing at any time.

With the development of urban and rural integration and rural urbanization in the new era, many villages began to transform into cities, and the characteristics of the villages gradually disappeared. For example, the natural environment of rural areas was gradually replaced by industrial machines, and fewer and fewer farmers are engaged in agriculture in rural areas. In this process of urbanization, the interests of the peasants are difficult to balance and deal with, which will lead to disordered rural communities and a tendency to dispersed population. At this time, the resources of the village elites will be less and less, so the space in which it works will become smaller and smaller.

In the new era, many village elites firstly went out of the countryside to study in other cities, but in the process of studying, they may lose contact with rural communities, so that some practical problems in their returning to hometown arise: having been accustomed to the city life, they have to get used to rural life again, they cannot immediately gain the trust of rural communities after returning home, and communication conflict me occur because the level of knowledge is not at the same height. From the perspective of rural grassroots cadres, there are still problems with the views of the village elites since many grassroots cadres do not accept or pay attention to the village elites.

In the traditional period, the squires got the acquiescence of the imperial power, so they decided the authority of its governance, but nowadays new village elites returned to their hometown without the institutional authority guarantee, coupled with some pseudo-village elites who pursued the interests, which blurs the correct view of rural communities and grassroots cadres on the village elites still more. In this way, after returning home, the village elites spend a lot of time and energy to rebuild the trust of the countryside and their prestige, which greatly affects the progress of the village elites' participating in the governance of rural communities.

\section{The Path and Method of NeW Village Elites' PARTICIPATION IN RURAL COMMUNITY GOVERNANCE IN THE NEW ERA}

As mentioned above, there are still some difficulties and problems need to be solved in new village elites' participation in the governance of rural communities in the new era. This paper only studies and analyzes the ways in which new village elites participates in rural community governance, and puts forward some solutions for problems encountered.

From the perspective of the government, in the context of urban-rural integration and rural urbanization, it is necessary to clarify that such a modernization process can't eliminate the original development characteristics of the village. General Secretary Xi Jinping has published such views in recent years when carrying out investigation: in the process of promoting rural modernization, we must pay attention to overall planning, to the characteristics and laws of the development of the village itself instead of messing up. We must pay attention to preserving the natural environment and style of the village and retaining the taste of the countryside. Therefore, the government should combine the characteristics of different rural areas with the modernization process of urban-rural integration and rural urbanization, and let the village elites exert their advantages and characteristics, so that they can better participate in the governance of rural communities in such a suitable development rhythm. Secondly, the government should encourage the village elites to return to their hometowns to make contributions to the governance of rural communities. They should actively consider and deal with the practical problems encountered when the village elites return to villages, simplify some of the formalities, and arrange the basic life issues of village elites after they return townships and hometowns in time. Furthermore, the government should convey the role and importance of the village elites within the grassroots level, reduce the misunderstanding of the grassroots cadres to the village elites, raise the cognitive level of the rural peasants in the rural communities for village elites and enhance the rural community's sense of identity with the village elites. The most important thing is that the government should establish a management system for the village elites based on the rule of law, so that it can form a reasonable supervision of the township, and also provide a certain information platform for the village elites to return home, so that even if they do not return home, they can also contribute well to the governance of rural communities in other cities.

From the perspective of village elites themselves, they should actively maintain the connection with the countryside when studying outside, actively use the knowledge and resources acquired from outside school to actively go deep in the interior of the community and deepen their understanding of the actual situation within the community through interviews and publicity. Secondly, under the background of the new era, the village elites should actively respond to various policies put forward by the country, such as the "rural revitalization" policy proposed by the 19th National Congress, actively innovate, and propose their cutting-edge approach for rural community governance. In addition to the economical and institutional management of the community, they must actively participate in communicating advanced culture such as socialist core values, inheriting local culture, and preaching education of the rule of law, and improve the overall quality of rural communities from culture and the rule of law.

\section{CONCLUSION}

In summary, in the new era, how village elites can be better involved in the governance of rural communities requires the cooperation and joint efforts of the government and the village elites These efforts will not bring the governance of rural communities sudden effect in a single 
day, but it is a long-term process of persistence and innovation, which requires the attention of people from all walks of life.

\section{REFERENCES}

[1] Yan Deru. Promoting Contemporary Chinese Rural Governance with New Village Elites[J]. Theoretical Investigation, 2016, (1): 17-21.

[2] Fu Cuilian. The Change of China's Rural Governance Model—The Governance of New Village Elites with Dilemma and Endogenous Authority[J]. Research of Local Governance, 2016,(1):67-73.

[3] Li Zengyuan. On the Historical Evolution and Modern Turn of Rural Community Governance in China[J]. Theory and Reform, 2016, (4): 58-66.

[4] Li Zengyuan. Reform and Innovation of Rural Community Governance in an Open and Floating Society [J]. Socialist Study, 2016, (2): 121-127.

[5] Wang Wenfeng, New Village Elites' Role, Predicament and Countermeasures in Rural Governance [J], Future and Development, 2016, (8): 87-91.

[6] Yang An, Han Qi. Path Choice of Rural Governance in the New Period [N]. People's Tribune, 2017. 